\title{
Exogenously applied salicylic acid maintains redox homeostasis in salt-stressed Arabidopsis gr1 mutants expressing cytosolic roGFP1
}

\author{
Jolán Csiszár ${ }^{1} \mathbb{D} \cdot$ Szilvia Brunner ${ }^{1}$. Edit Horváth ${ }^{1} \cdot$ Krisztina Bela $^{1} \cdot$ Petra Ködmön ${ }^{1} \cdot$ Riyazuddin Riyazuddin $^{1}$. \\ Ágnes Gallé ${ }^{1}$. Ágnes Hurton ${ }^{1} \cdot$ Csaba Papdi $^{2} \cdot$ László Szabados $^{2} \cdot$ Irma Tari $^{1}$
}

Received: 1 December 2016 / Accepted: 18 June 2018

○) Springer Nature B.V. 2018

\begin{abstract}
Exogenous salicylic acid (SA) can be used for chemical hardening to alleviate oxidative stress in plants exposed to salinity. The treatment of 5-week-old Arabidopsis thaliana plants with increasing doses of SA alters the ascorbate (ASC) and glutathione (GSH) pools, and modulates their redox status and the activity of several antioxidant enzymes, such as ascorbate peroxidase (APX) and glutathione reductase (GR). To investigate the role of GR in the maintenance of cytoplasmic redox homeostasis after hardening by SA, wild type (WT) and grl mutant plants, expressing the cytoplasmic redox-sensitive green fluorescent protein (c-roGFP1), were pre-treated with $10^{-7}$ and $10^{-5} \mathrm{M}$ SA for 2 weeks and subsequently exposed to $100 \mathrm{mM} \mathrm{NaCl}$. The redox status of the salt-stressed WT plants became more oxidized, which was prevented by pretreatment with $10^{-5} \mathrm{M} \mathrm{SA}$. The grl mutants showed more positive redox potential than WT plants, which could be reversed by treatment with $10^{-5} \mathrm{M} \mathrm{SA}$. In mutants, the increased GSH levels may have compensated for the deleterious effect of GR deficiency and stabilized the redox potential in plants exposed to salinity. The ASC regeneration in WT plants shifted from the GSH-dependent dehydroascorbate reductase (DHAR) reaction to the $\mathrm{NAD}(\mathrm{P}) \mathrm{H}$-dependent monodehydroascorbate reductase (MDHAR) activity during chemical hardening, which contributed to the preservation of the GSH pool in plants under salt stress. Our results suggest that the maintenance of GSH levels and redox homeostasis by SA-mediated hardening play a major role in priming and defending against salt stress.
\end{abstract}

Keywords Ascorbate-glutathione pool $\cdot$ Glutathione reductase $\cdot$ Redox homeostasis $\cdot$ Redox-sensitive GFP1 Salt stress

$\begin{array}{ll}\text { Abbreviations } \\ \text { APX } & \text { Ascorbate peroxidase } \\ \text { ASC } & \text { Ascorbate } \\ \text { c-roGFP1 } & \begin{array}{l}\text { Cytoplasmic redox-sensitive green fluorescent } \\ \text { protein }\end{array} \\ \text { DHAR } & \text { Dehydroascorbate reductase } \\ E_{G S H} & \text { Glutathione reduction potential }\end{array}$

Jolán Csiszár and Szilvia Brunner contributed equally to this work

Electronic supplementary material The online version of this article (https://doi.org/10.1007/s10725-018-0420-6) contains supplementary material, which is available to authorized users.

Jolán Csiszár

csiszar@bio.u-szeged.hu

1 Department of Plant Biology, Faculty of Sciences, University of Szeged, Közép fasor 52., Szeged 6726, Hungary

2 Institute of Plant Biology, Biological Research Centre of HAS, Temesvári krt. 62., Szeged 6726, Hungary
$E_{\text {roGFP }} \quad$ Reduction potential of roGFP1

GR Glutathione reductase

grl Glutathione reductasel mutant

GSH Reduced glutathione

GSSG Glutathione disulphide, oxidized glutathione

MDHAR Monodehydroascorbate reductase

NPR1 Non-expressor of pathogenesis-related genes 1

ROS Reactive oxygen species

SA Salicylic acid

TRX Thioredoxin

WT Wild type

\section{Introduction}

Reduction-oxidation (redox) reactions are fundamental metabolic processes through which cells convert and distribute the energy that is necessary for growth and development, even in the presence of unfavourable environmental factors (Noctor 2006). Cellular redox homeostasis is an essential buffering 
mechanism that prevents excessive reduction or oxidation (Foyer and Noctor 2011). There is a close interplay between individual redox-active molecules, while their status can influence plant metabolism and environmental responses. Key redox compounds in the soluble phase in living tissues are $\mathrm{NADH}, \mathrm{NADPH}$, glutathione and ascorbate, all of which are linked with the production or enhanced availability of reactive oxygen species (ROS). During the catalytic reduction of $\mathrm{O}_{2}$ to $\mathrm{H}_{2} \mathrm{O}$, reactive oxygen intermediates, e.g., superoxide radical $\left(\mathrm{O}_{2}^{-}\right)$, hydrogen peroxide $\left(\mathrm{H}_{2} \mathrm{O}_{2}\right)$ and hydroxyl radical $(\mathrm{OH})$ can be formed. ROS generation accompanies normal aerobic metabolism, but its level typically increases in plants exposed to abiotic and biotic stresses (Foyer and Noctor 2005). Unbalanced generation of ROS induces the detrimental oxidation of macromolecules, including DNA, proteins and lipids. In order to keep ROS levels tightly regulated and minimize ROSderived damage, different non-enzymatic antioxidants (such as ASC, glutathione, carotenoids and tocopherols) and antioxidative enzymes have evolved in aerobic organisms (Foyer and Noctor 2005). In general, antioxidative systems are constitutively present, but show increased activity in response to stresses. On the other hand, endogenous change in oxidant levels can fulfil signalling functions, playing a positive role in adaptation to changed environmental conditions, including high salinity (Dat et al. 2000; Boguszewska and Zagdańska 2012; Baxter et al. 2014).

Induction of defence mechanisms, which empowers the stress tolerance, may be triggered, not only endogenously but also exogenously. Certain natural or synthetic compounds applied in the range of $\mu \mathrm{M}$ concentrations prior to stress events can lead to enhanced stress tolerance and be effectively used as priming agents (Tari et al. 2002; Beckers and Conrath 2007; Horváth et al. 2007; Popova et al. 2009; Gémes et al. 2011; Antoniou et al. 2016; Savvides et al. 2016). Plant priming (also known as hardening) improves the tolerance of plants towards adverse conditions and thus is of great importance in plant stress physiology and crop stress management.

Chemical priming agents can be reactive oxygen, nitrogen and sulphur species, as well as their donors, melatonin, polyamines, proline or plant hormone salicylic acid (SA) (Savvides et al. 2016). Plants in a primed state have the ability to alleviate primary or secondary oxidative stress-induced damage better than unprimed controls. Several reports have revealed protein modifications and transcriptional changes during chemical hardening, which affect antioxidant machinery and cell redox homeostasis (Tanou et al. 2012; Horváth et al. 2015; Tari et al. 2015; Savvides et al. 2016). Nevertheless, the mode of action of the priming agents and the mechanisms leading to the primed state are not fully understood.

Salicylic acid is known to reduce oxidative damage caused by environmental stresses, such as chilling and salinity, through modulating activities of key ROS detoxifying enzymes (Janda et al. 1999; Szepesi et al. 2009; Hayat et al.
2010; Horváth et al. 2015; Tari et al. 2015). Some of the SA-promoted changes in antioxidant enzyme activities derive from the altered transcriptional activity of these genes. Additionally, SA can influence an array of developmental and physiological processes. The effect of SA depends on the mode of application and the overall physiological condition of the plant (reviewed in Horváth et al. 2007; Hayat et al. 2010). Salicylic acid activates defence signalling pathway(s) through the NPR1 (non-expressor of pathogenesis-related genes1) signalling protein, which is normally inactive, due to forming oxidized cytosolic oligomer complexes through intermolecular disulfide bonds, but can be activated by releasing the monomer forms by reduction (Mou et al. 2003; Tada et al. 2008). The genetic inhibition of glutathione (GSH) accumulation in Arabidopsis thaliana controlled SA biosynthesis and it led to lower SA levels and a reduced expression of SA-dependent PR genes in GSH-deficient $c a d 2$ mutants (Han et al. 2013). The same authors demonstrated that using conditional catalase-deficient cat 2 Arabidopsis mutants for $\mathrm{H}_{2} \mathrm{O}_{2}$-triggered modulation of GSH content could be perceived by the cells as a signal. They revealed that GSH had a key influence on isochorismate synthasedependent SA synthesis and accumulation in this system, and acted independently of its antioxidant function in transmitting $\mathrm{H}_{2} \mathrm{O}_{2}$ signals. It was also shown that most of the effects of $c a d 2$ mutation on $\mathrm{H}_{2} \mathrm{O}_{2}$-triggered responses were distinct from those produced by mutations for glutathione reductase1 ( $g r l$ ) or NPRl. Thus, GSH accumulation and redox status are closely linked to SA synthesis and signalling.

Besides the amount of total glutathione, the ratio of the reduced form (GSH) and the oxidized glutathione disulphide (GSSG) can be an effective marker of cellular redox homeostasis, which also occurs in ROS perception in plants (Foyer and Noctor 2005; Noctor et al. 2012).

GR is known to play an essential role in upholding the reduced glutathione (GSH) pool in cell compartments (Noctor et al. 2011). GSSG is normally reduced to GSH by two GR isoforms encoded by two genes in the A. thaliana genome (AT3G54660, AT3G24170). GR1 is predominantly cytosolic, while GR2 is targeted to chloroplasts and mitochondria, although the GR1 protein can also be detected in peroxisome and nuclei (Jimenez et al. 1997; DelormeHinoux et al. 2016). The $g r l$ mutant is able to undergo normal development despite a reduction in GR activity by $65 \%$ and the lower GSH/GSSG ratio, while the $g r 2$ deletion mutant had a lethal phenotype displaying growth arrest at the stage of early embryo development (Tzafrir et al. 2004; Diaz-Vivancos et al. 2015).

Increased GR activity can alter the redox state of important components in the electron transport chain and often confers stress tolerance (Tsai et al. 2005; Gill et al. 2013). Using tobacco chloroplastic GR RNAi plants, it was shown that the regeneration of glutathione by GR is an important 
reaction in protecting against oxidative stress, even by maintaining the ascorbate pool and ascorbate redox state (Ding et al. 2009). Beside affecting glutathione regeneration, a decrease in GR activity was found to influence ASC regeneration and total ascorbate content in antisense transgenic tomato lines, which resulted in the greater accumulation of $\mathrm{H}_{2} \mathrm{O}_{2}$ and enhanced sensitivity towards chilling stress (Shu et al. 2011). Using grl and catalase 2 grl (cat2grl) double mutants, Mhamdi et al. (2010) found that GR1 plays a specific role in $\mathrm{H}_{2} \mathrm{O}_{2}$ responses when intracellular $\mathrm{H}_{2} \mathrm{O}_{2}$ production is increased, particularly under biotic stresses. The characterization of $g r l$ deletion mutants revealed that the whole-cell GSSG level increased in leaves of grl mutants, compared to those of the WT, but the mutation did not affect the amount of GSH (Marty et al. 2009).

To investigate the redox status of plants, the redox-sensitive green fluorescent protein (roGFP) reporter system was developed, which can be targeted selectively to the cytosol or to other cell compartments (Hanson et al. 2004; Jiang et al. 2006; Schwarzländer et al. 2008). The structure-dependent shift in the protonation status of the chromophore in the modified GFP protein is suitable for ratiometric analysis. The change in GFP-derived fluorescence in transgenic plants expressing roGFP depends on the reduction potential of the glutathione buffer $\left(E_{G S H}\right)$, based on specific interaction with glutaredoxins (Meyer et al. 2007). The determination of the fluorescent intensity of the fully reduced and fully oxidized form of the fluorescent probe enables quantitative monitoring of reduction potential $\left(E_{r o G F P}\right)$ without disturbing the cell (Meyer et al. 2007; Schwarzländer et al. 2008).

According to our earlier results, the 3-week-long pretreatment of tomato with $10^{-4}$ M SA increased the efficiency of enzymatic and non-enzymatic antioxidants and provided protection against $100 \mathrm{mM} \mathrm{NaCl}$ applied to a hydroponic culture (Szepesi et al. 2008, 2009; Gémes et al. 2011; Csiszár et al. 2014). The increased ASC and glutathione pool was suggested to have a central role in the determination of such stress responses in tomato (Tari et al. 2015). We have also successfully applied SA for chemical hardening in A. thaliana. The pretreatment of 5-week-old Arabidopsis plants with $10^{-6}$ and $10^{-5} \mathrm{M} \mathrm{SA}$ resulted in enhanced tolerance towards subsequent salt stress (Horváth et al. 2015). While lower concentrations were inefficient, higher concentrations induced the death of plants. These results indicated that increased glutathione transferase (GST) and glutathione peroxidase (GPOX) activities may play an important role in acclimation; moreover, the modified GST expressions suggested an altered signalling in SA-treated plants during salt stress (Horváth et al. 2015).

Maintaining a high GSH/GSSG ratio was shown to play an important role in the salt tolerance of plants (Shalata and Neumann 2001). GR was important for upholding the GSH pool and strengthening the antioxidative capacity of plants in adapting to high salinity (Noctor et al. 2011; Gill et al. 2013).

Here, we report that exogenous SA can alter GSH and ASC pools and modulate the redox status, thus causing an induced state in a concentration-dependent manner. The redox-sensitive green fluorescent protein with cytoplasmic localization (c-roGFP1) was introduced into the $g r l$ insertional mutants to reveal the role of cytoplasmic GR in the maintenance of redox homeostasis in $g r l$ insertional mutants. In the first set of experiments, the concentration dependency of SA-induced changes in reduced and oxidized pools of ASC and GSH, as well as in the activity of the enzymes participating in their conversions (ascorbate peroxidase: APX; monodehydroascorbate reductase: MDHAR; dehydroascorbate reductase: DHAR; and glutathione reductase: GR) were monitored in WT plants for 3 weeks. In order to compare the pools and redox status of GSH and ASC in WT and mutant plants, the redox status of these non-enzymatic antioxidants was analysed in the second set of experiments. The $g r 1$ mutants expressing c-roGFP1 and their respective controls were pretreated with $10^{-7}$ and $10^{-5} \mathrm{M}$ concentrations of SA (the earlier was ineffective, the latter caused successful hardening against salt stress) for 2 weeks. Then, the plants were exposed to high salinity caused by $100 \mathrm{mM}$ of $\mathrm{NaCl}$ and the redox status of their leaves was determined after 1 week.

In this study, we revealed the concentration dependency of SA-induced changes in the redox status of leaf cells and their relationship with a successful acclimation of the pretreated plants exposed to high salinity.

It was found that the redox potential of the grl mutant cells was more oxidized than that of plants with WT GR1. Contrary to low SA concentration, the redox potential of plant cells pretreated with $10^{-5} \mathrm{M}$ SA was maintained at the level of untreated control under salt stress. This can be achieved by an increased GSH pool, suggesting that the mutation in the cytoplasmic isoenzyme of GR can be compensated by the induction of GSH synthesis and accumulation.

\section{Materials and methods}

\section{Plant material and growth conditions}

Our experiments were performed on A. thaliana L. (ecotype Columbia) plants (Col-0 WT). The glutathione reductase 1 ( $g r l)$ mutant plants (Marty et al. 2009) were obtained from the Salk Collection, the seeds of plants expressing cytosolic redox-sensitive green fluorescent protein (c-roGFP1) were kindly provided by Dr. M. Schwarzländer, and the c-roGFP1 was introduced into the $g r l$ mutants by crossing. The plants were grown in Hoagland solution in a growth chamber (Fitoclima S $600 \mathrm{PLH}$, Aralab, Portugal) at $21^{\circ} \mathrm{C}$, under $100 \mu \mathrm{mol} \mathrm{m} \mathrm{m}^{-2} \mathrm{~s}^{-1}$ of light intensity with a $10 / 14 \mathrm{~h}$ day/night 
photoperiod. The relative humidity was $70 \%$. Five-week-old plants were treated by adding SA solutions to the hydroponic medium.

\section{Experimental systems and treatments used}

Five-week-old hydroponically grown Arabidopsis plants were treated with $10^{-8}-10^{-5} \mathrm{M}$ SA concentrations for 2 weeks, then exposed to $100 \mathrm{mM} \mathrm{NaCl}$ for 1 week (Horváth et al. 2015). SA was present in the culture solution during salt treatment. In the present study, we applied two different experimental systems. Firstly, the effect of 3-weeklong $10^{-8}-10^{-5} \mathrm{M}$ SA treatments was investigated on ASC and GSH levels, their redox status and the activity of some ASC- and GSH-related antioxidant enzymes. Samples were taken from fully expanded leaves and roots every week after the SA exposure. In the second set of experiments, the redox state of these main non-enzymatic antioxidants was investigated in $g r l$ mutants expressing c-roGFP1, which were pretreated with SA for 2 weeks and then with $100 \mathrm{mM} \mathrm{NaCl}$. Two concentrations of SA were selected, one of which caused successful hardening $\left(10^{-5} \mathrm{M}\right)$ against salt stress and the other, a lower SA concentration, which was inefficient $\left(10^{-7} \mathrm{M} \mathrm{SA}\right)$ for comparing the redox changes in plant cells. Samples were taken for the determination of roGFP redox potential $\left(E_{\text {roGFPl }}^{\prime}\right)$ from fully expanded leaves every week during this 3-week-long experiment. Detection of the ascorbate (ASC) and glutathione redox pairs in shoots and roots was performed 1 week after the treatment with $100 \mathrm{mM} \mathrm{NaCl}$ in plants with or without pretreatments. The experiments were repeated at least twice and the measurements were performed in three replicates, unless indicated otherwise.

\section{Ascorbate and glutathione extraction and determination}

ASC and glutathione contents were determined according to Tari et al. (2015). $500 \mathrm{mg}$ of leaf or root tissues were homogenized with $1 \mathrm{ml}$ of $5 \%$ trichloroacetic acid (TCA). The homogenate was centrifuged at $10,000 \times g$ for $20 \mathrm{~min}$ at $4{ }^{\circ} \mathrm{C}$ and the supernatant was used for further determinations. To assay total ASC, $100 \mu \mathrm{l}$ of $10 \mathrm{mM}$ dithiothreitol (DTT) was added to the extract, with the excess DTT removed by adding $100 \mu \mathrm{l}$ of $0.5 \%$ (w/v) $N$-ethylmaleimide (NEM). ASC concentrations were determined spectrophotometrically at $525 \mathrm{~nm}$. Dehydroascorbate (DHA) content was calculated as the difference between the concentration of total and reduced ASC.

Total and oxidized glutathione concentrations were measured spectrophotometrically using an enzymatic assay. To mask reduced glutathione, 4-vinylpyridine was added to the extract and incubated for $60 \mathrm{~min}$. The reaction mixture contained $100 \mathrm{mM}$ phosphate buffer (pH 7.5), $1 \mathrm{mM}$ 5,5'-dithiobis(2-nitrobenzoic acid) (DTNB), $1 \mathrm{mM} \mathrm{NADPH,}$ $1 \mathrm{U}$ of GR (baker's yeast, Sigma-Aldrich) and $20 \mu \mathrm{l}$ of the tissue extract in a $1 \mathrm{ml}$ volume. GSH content was calculated from the difference between the concentration of total and oxidized glutathione. Standard curves were obtained for total glutathione and GSSG within the $0-5 \mu \mathrm{M}$ range.

\section{Determination of antioxidant enzyme activities}

The enzyme activities were determined as published in Tari et al. (2015) with some modifications. $100 \mathrm{mg}$ of plant tissue were homogenized on ice in $1 \mathrm{ml}$ of $100 \mathrm{mM}$ phosphate buffer (pH 7.0) containing $1 \mathrm{mM}$ phenylmethylsulphonyl fluoride and $1 \%$ polyvinylpolypyrrolidone. For the ascorbate peroxidase (APX) assay, $1 \mathrm{mM}$ ASC was added to the extraction buffer. The homogenate was centrifuged for $20 \mathrm{~min}$ at $10,000 \times \mathrm{g}$ at $4{ }^{\circ} \mathrm{C}$ and the supernatant was used for enzyme activity assays.

APX (EC 1.11.1.11) activity was assayed according to the method reported by Nakano and Asada (1987). The hydrogen peroxide-dependent oxidation of ASC was followed by a decrease in the absorbance at $290 \mathrm{~nm}$ $\left(\varepsilon_{290}=14.0 \mathrm{mM}^{-1} \mathrm{~cm}^{-1}\right)$. APX activity was expressed as nmol ASC oxidized $\mathrm{min}^{-1} \mathrm{~g}^{-1}$ fresh weight (FW).

MDHAR (EC 1.6.5.4) activity was assayed spectrophotometrically by following the decrease in absorbance at $340 \mathrm{~nm}$ due to NADH oxidation as reported by Hossain et al. (1984). MDHA free radicals were generated by ascorbic acid oxidase (EC 1.10.3.3; Sigma-Aldrich) in the assay system. MDHAR activity (nmol $\mathrm{min}^{-1} \mathrm{~g}^{-1} \mathrm{FW}$ ) was calculated from the decrease in the NADH content by measuring the absorbance at $340 \mathrm{~nm}$ and using the $6.2 \mathrm{mM}^{-1} \mathrm{~cm}^{-1}$ extinction coefficient.

DHAR (EC 1.8.5.4) activity was assayed as published in Csiszár et al. (2014). The enzyme activity (nmol min ${ }^{-1} \mathrm{~g}^{-1}$ FW) was calculated from the increase in the ASC content by measuring the absorbance at $265 \mathrm{~nm}$ and using the $14.0 \mathrm{mM}^{-1} \mathrm{~cm}^{-1}$ extinction coefficient.

GR (EC 1.8.1.7) activity was determined by measuring the absorbance increment at $412 \mathrm{~nm}$ when DTNB was reduced by GSH, generated from GSSG (Tari et al. 2015). The activity was calculated as the amount of reduced DTNB

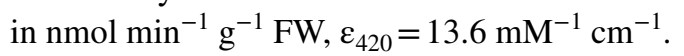

\section{Detection of the redox potential by ratiometric measurements of the fluorescent probe}

To determine the glutathione redox potential, we used Arabidopsis plants containing the c-roGFP1 redox sensor protein and the fluorometer-based method (Rosenwasser et al. 2010). The ratio of $I_{405} / I_{488}$ can provide information about the relative redox status of cells. Determination of the fluorescent intensity of the fully reduced and fully oxidized forms of the probe enables quantitative monitoring 
of $E_{G S H}$, which displays the differences in redox potential throughout the cell (Meyer et al. 2007; Schwarzländer et al. 2008). The c-roGFP1-harbouring plants were crossed with grl insertional mutants, and the $\mathrm{T}_{3}$ generation homozygous for the T-DNA insertion and containing the roGFP1-coding sequence was also used for in vivo redox potential detections. In the case of each treatment, 12 pieces of leaf discs, each with a diameter of $0.6 \mathrm{~cm}$, were cut out from rosettes and floated on $200 \mu \mathrm{l}$ of sterile distilled water, one by one, in a 96-well, flat-bottomed black plate (Greiner Bio-One) with their abaxial side facing upwards. Fluorescence measurements were performed on a FLUOstar OPTIMA fluorescence plate reader (BMG Labtech, Durham, NC, USA) in the Department of Microbiology at the University of Szeged, Hungary. 405 and $485 \mathrm{~nm}$ filters were used for excitation, and fluorescence values were detected with a $530 \mathrm{~nm}$ emission filter. Using endpoint measurements, the fluorescence of the basic state was firstly measured, then the leaf discs were treated with $200 \mu \mathrm{l}$ of $200 \mathrm{mM} \mathrm{H}_{2} \mathrm{O}_{2}$ for $15 \mathrm{~min}$ to determine the fully oxidized status of the leaves. After washing five times with sterile distilled water, the leaf discs were treated with $200 \mu \mathrm{l}$ of $100 \mathrm{mM}$ DTT for $90 \mathrm{~min}$ to measure the fluorescence when the roGFP1 was fully reduced. For background correction, three leaf discs of each treated Col-0 plant were used.

The redox potential was calculated using the formula provided by Schwarzländer et al. (2008). The degree of oxidation $(O x D)$ of the roGFP1 was:

$O x D_{\text {roGFP } 1}=\left(R-R_{\text {red }}\right) /\left(\frac{I_{485 o x}}{I_{485 r e d}}\right)\left(R_{o x}-R\right)+\left(R-R_{\text {red }}\right)$

where $R$ is the ratio of excitation at $405 / 485 \mathrm{~nm} ; R_{\text {red }}$ is the ratio of the fully reduced form using $100 \mathrm{mM}$ DTT; $R_{\mathrm{ox}}$ is the ratio of the fully oxidized form using $200 \mathrm{mM} \mathrm{H}_{2} \mathrm{O}_{2}$; $I_{485 \mathrm{ox}}$ is the intensity at $485 \mathrm{~nm}$ for the fully oxidized form; $I_{485 \text { red }}$ is the intensity at $485 \mathrm{~nm}$ for the fully reduced form.

The redox potential was determined using the following equation:

$E^{\prime}=E_{0 r o G F P 1}-\frac{2.303 R T}{z F} \log _{10} \frac{1-O x D_{r o G F P 1}}{O x D_{r o G F P 1}}$

where $\mathrm{E}_{0 \text { roGFP }}$, the midpoint potential of roGFP1, is $-288 \mathrm{mV}$ at $30{ }^{\circ} \mathrm{C} \mathrm{pH} \mathrm{7;R}$ is the gas constant $\left(8.315 \mathrm{~J} \mathrm{~K}^{-1} \mathrm{~mol}^{-1}\right) ; T$ is the absolute temperature $(298.15 \mathrm{~K}) ; z$ is the number of transferred electrons (2); $F$ is the Faraday constant $\left(9.648104 \mathrm{C} \mathrm{mol}^{-1}\right)$.

\section{Statistical analysis}

Statistical analysis was performed with SigmaPlot 11.0 software by using one-way ANOVA, followed by Duncan's test, with differences considered significant at $\mathrm{P} \leq 0.05$. Data presented here are the means \pm SD of at least three measurements, unless indicated otherwise.

\section{Results}

\section{SA may enhance the ascorbate and glutathione levels in Arabidopsis}

The treatment of 5-week-old Arabidopsis plants with $10^{-8}-10^{-5}$ M SA for 3 weeks altered the GSH and ASC pools and modulated their redox status in a concentrationdependent manner. In untreated control plants, ASC content was significantly increased in the shoots and reduced in the roots, while DHA amounts did not change as a function of time (Fig. 1a-c). Addition of SA reduced the ASC levels in shoots, while the amount of oxidized DHA slightly increased (Fig. 1a, c). In the roots, ASC and DHA levels did not change in the presence of SA with the exception of the higher SA doses $\left(10^{-6}\right.$ and $\left.10^{-5} \mathrm{M} \mathrm{SA}\right)$, which increased the amounts of the reduced and oxidized ASC forms transiently in the 2nd week of the treatments (Fig. 1b, d). The GSH pool was considerably elevated in the shoots and slightly in the roots by SA treatments, while the amount of GSSG was reduced in shoots and transiently enhanced in roots in the 2nd week of $10^{-6}-10^{-5}$ M SA treatments (Fig. 1e-h). The highest increment in the GSSG level was at the end of the second week, reaching values that were ten times higher than in the untreated control (Fig. 1h).

\section{SA increased GR and inhibited DHAR activity, while other ASC-related enzymes showed only moderate changes}

To analyse the role of the antioxidant enzymes in this process, the activities of several ASC- and glutathionerelated enzymes were measured during the 3-week-long SA treatment. APX activity was only moderately enhanced by SA in shoots, with the exception of $10^{-8}-10^{-7} \mathrm{M} \mathrm{SA}$ treatments, which increased this activity almost two- to threefold after 3 weeks (Fig. 2a). In the roots, APX activity was, in general, slightly reduced by SA, with the exception of $10^{-5} \mathrm{M} \mathrm{SA}$, which transiently enhanced it after 2 weeks (Fig. 2b). MDHAR activity exhibited only small changes during the SA treatments, both in the shoots and the roots of untreated and SA-treated Col-0 plants (Fig. 2c, d). DHAR activity, which decreased with time in untreated control shoots and roots, was more pronounced in the presence of $10^{-8}-10^{-5}$ M SA (Fig. 2e, f). The activity of GR in shoots showed certain fluctuations as a function of time in response to lower SA concentrations, but was induced by higher doses of SA $\left(10^{-6}-10^{-5} \mathrm{M}\right)$; however, in roots it was gradually induced (Fig. $2 \mathrm{~g}, \mathrm{~h}$ ). 
a

Shoot

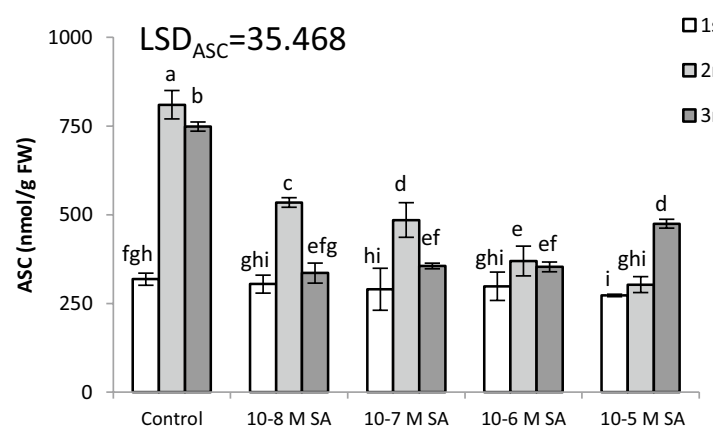

C

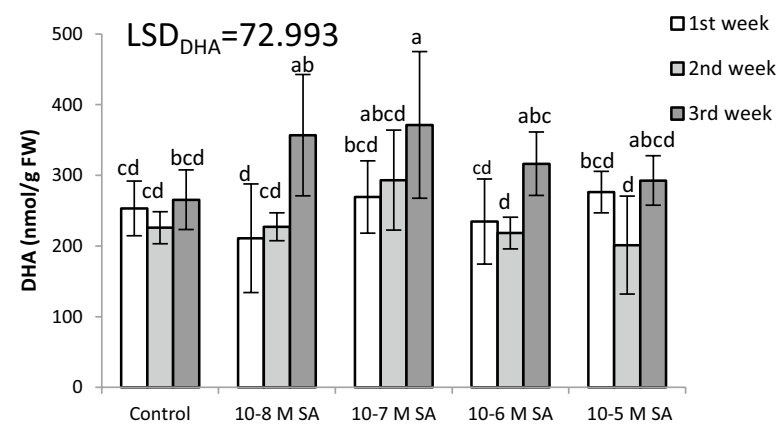

e

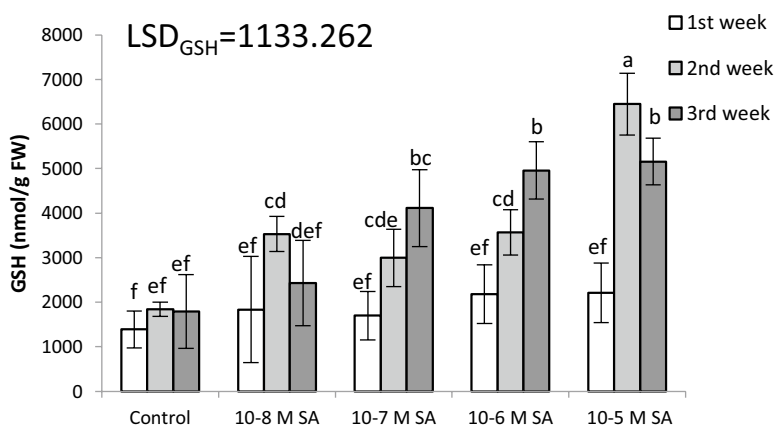

g

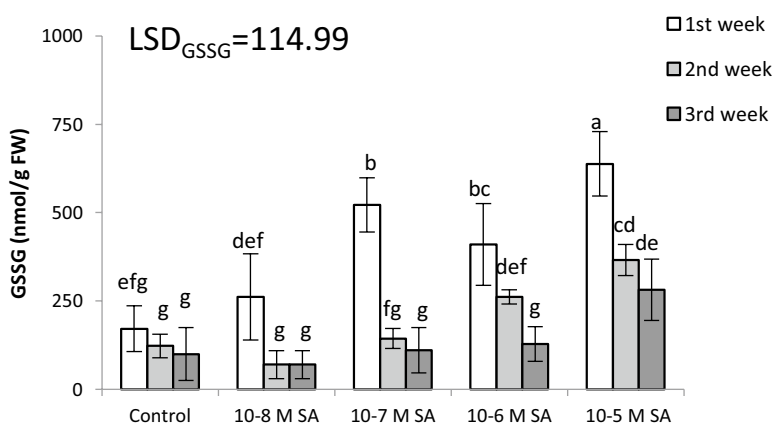

b

Root

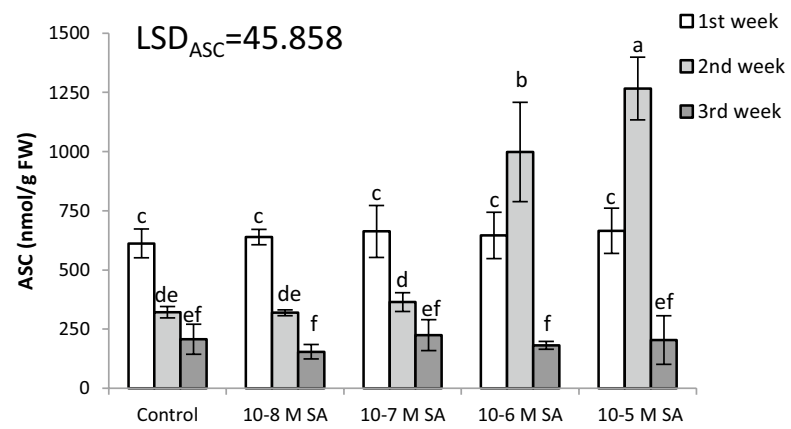

d

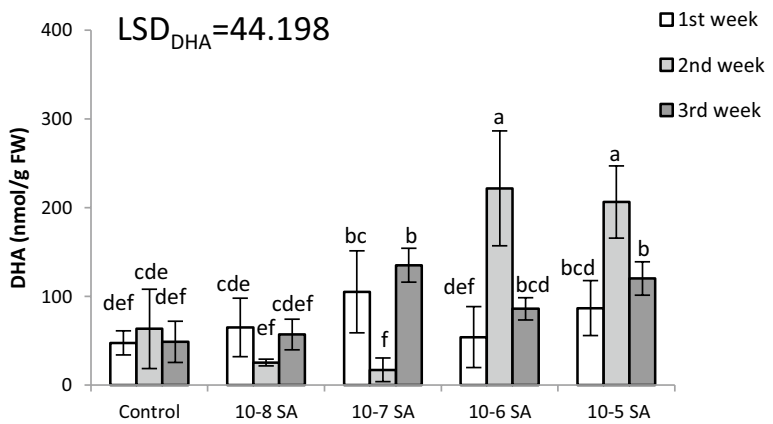

f

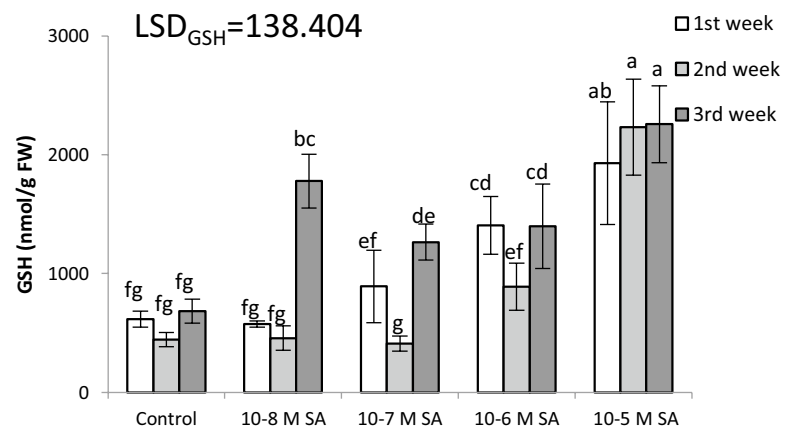

h

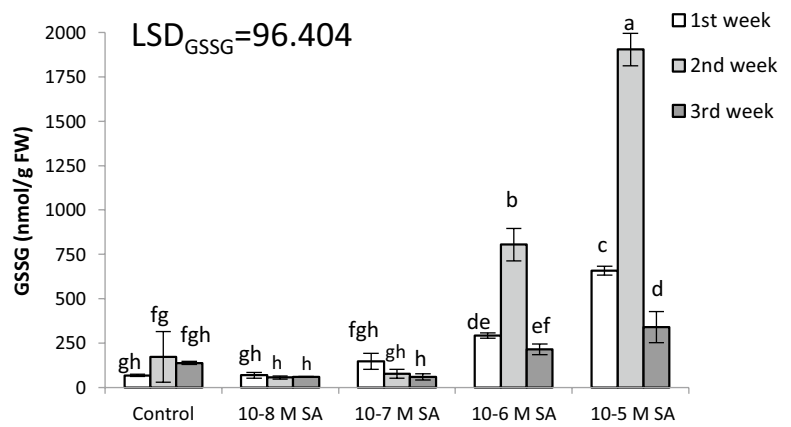


४Fig. 1 Changes in reduced and oxidized ascorbate and glutathione (ASC, DHA, GSH and GSSG, respectively) contents in the leaves and roots of 8-week-old A. thaliana plants treated with $10^{-8}-10^{-5} \mathrm{M}$ SA. Data are means \pm SD. Columns with different letters are significantly different at $\mathrm{p}<0.05$, determined by Duncan's test. Control values before treatments were: a $275.44 \pm 27.5$, b $694.40 \pm 54.1$, c $248.20 \pm 14.9$, d $53.15 \pm 6.7$, e $1672.8 \pm 188.9$, f $580.7 \pm 11.7$, g $147.57 \pm 16.3$, h $100.11 \pm 26.1 \mathrm{nmol} \mathrm{g}^{-1} \mathrm{FW}$, respectively

\section{SA-treated gr1 mutants can maintain their redox status under salt stress}

The role of the glutathione pool and the GR enzyme activity in the control of redox potential and chemical hardening was investigated using Arabidopsis grl insertional mutants expressing the roGFP1 redox sensor protein. In these experiments, roGFP1-containing Arabidopsis plants were used as controls. Redox potentials of cells determined by roGFP1-derived fluorescence became less negative as a function of time, but the values were not significantly different in leaf discs excised from roGFP1-expressing WT plants or $g r l$ mutants under control conditions or after treatment with $10^{-7} \mathrm{M} \mathrm{SA}$. Interestingly, treatment with $10^{-5} \mathrm{M}$ SA resulted in more oxidized $E_{\text {roGFP }}^{\prime}$ (i.e., smaller negative values) after 2 weeks in both genotypes (Table 1 ).

When redox potential was measured in roGFP-expressing plants with WT cytosolic GR1 after a 1-week-long exposure to salt stress, $E^{\prime}$ became more positive. Pretreatment with $10^{-7}$ or $10^{-5} \mathrm{M} \mathrm{SA}$ for 2 weeks reduced this shift (Fig. 3a). The redox status of the salt-stressed plants without SA pretreatment became more oxidized, namely, the $E^{\prime}$ became less negative by $20 \mathrm{mV}$. Pretreatment with $10^{-7} \mathrm{M}$ SA led to a smaller shift $(10 \mathrm{mV})$, while the $E^{\prime}$ in plants pretreated with $10^{-5} \mathrm{M}$ SA did not differ significantly from that of the untreated controls, indicating that they were able to restore their redox potential values (Fig. 3a).

In the $g r l$ mutant background, a more oxidized redox status was detected, which became more negative upon treatment with $10^{-5} \mathrm{M} \mathrm{SA}$. The $g r 1$ mutants had a more positive redox potential without any treatment $(-268 \mathrm{mV})$, which was not changed significantly by salt stress alone, but became more positive $(-250 \mathrm{mV})$ after applying $100 \mathrm{mM}$ $\mathrm{NaCl}$ to plants pretreated with $10^{-7} \mathrm{M} \mathrm{SA}$. When mutant plants were hardened by pretreatment with $10^{-5} \mathrm{M} \mathrm{SA}$, the shift in redox potential was smaller and the $E^{\prime}$ values were close to the levels of untreated plants (Fig. 3b).

\section{Increase in GSH levels can contribute to redox potential maintenance in SA-treated gr 1 mutants under salt stress}

The investigation into the effects of 1-week-long salt stress on the ASC pool of the roGFP1-expressing Col-0 plants revealed that, while the amount of DHA did not change significantly due to the applied $\mathrm{NaCl}$ or $\mathrm{SA}$ treatments, the reduced form of ASC increased in the shoots (Fig. 4a). The highest (about a threefold) increase can be observed after treatment with $10^{-5} \mathrm{M} \mathrm{SA}$, but a twofold ASC accumulation was detected, even after applying $100 \mathrm{mM} \mathrm{NaCl}$ for 1 week to the plants expressing roGFP1, which were pretreated with $10^{-5} \mathrm{M}$ of SA (Fig. 4a). The salt treatment increased the level of GSSG in plants without SA pretreatment and in those pretreated with $10^{-7} \mathrm{M} \mathrm{SA}$, but not in the shoots pretreated with $10^{-5} \mathrm{M} \mathrm{SA}$ (Fig. 4c). The amount of GSH was elevated by both $\mathrm{NaCl}$ and $\mathrm{SA}$; the highest (threefold) increment was measured in the shoots pretreated with $10^{-5} \mathrm{M} \mathrm{SA}$ after salt treatment, which ensured that the GSH/GSSG ratio remained close to the control (Fig. 4c). In the roots, DHA and GSSG levels increased by salt or SA treatments to a higher extent than in the shoots. While the amount of the reduced form of ASC was enhanced only in the salt-stressed control and in plants pretreated with $10^{-7} \mathrm{M} \mathrm{SA}$, the amount of GSH increased after pretreatment with $10^{-5} \mathrm{M} \mathrm{SA}$, while its high level was maintained, even after applying $100 \mathrm{mM} \mathrm{NaCl}$ for 1 week (Fig. 4e, g).

In general, the level of these antioxidants in the $\mathrm{grl}$ mutants changed in a similar manner to that in WT plants expressing roGFP1; however, a comparison of the ASC and glutathione pools in the shoots of non-treated plants revealed that the total amount of these non-enzymatic antioxidants was higher in $g r l$ mutants than in WT plants (149 and $142 \%$, respectively) (Fig. 4a, d). The ratio of ASC/ DHA in the $g r l$ plants was usually comparable to that of the WT plants, or even higher. The GSH/GSSG ratio was lower in $g r l$ mutants than in the WT (one-seventh in shoots and one-third in roots under control conditions). The amount of GSH was elevated in the $g r l$ plants, compared to the WT, after SA and salt treatments, with the exception of the salt-stressed plant roots pretreated with $10^{-7} \mathrm{M} \mathrm{SA}$ (Fig. 4).

\section{Discussion}

SA was shown to be a signal for the development of systemic acquired resistance (SAR), which prevents further infection of the plant by pathogens, as well as potentially providing tolerance against various environmental stresses (Shirasu et al. 1997). The relevant role of ROS was proven in the activation of defence and acclimation mechanisms in systemic or non-challenged tissues (SAR or systemic acquired acclimation, SAA), and similarly in the process of priming or chemical hardening (Baxter et al. 2014; Horváth et al. 2015; Antoniou et al. 2016). ROS, especially $\mathrm{H}_{2} \mathrm{O}_{2}$ as signalling molecules, may reversibly modify amino acids, such as Cys, the tripeptide GSH and critical thiol groups in a range of proteins. Among the primary targets of ROS are 
a

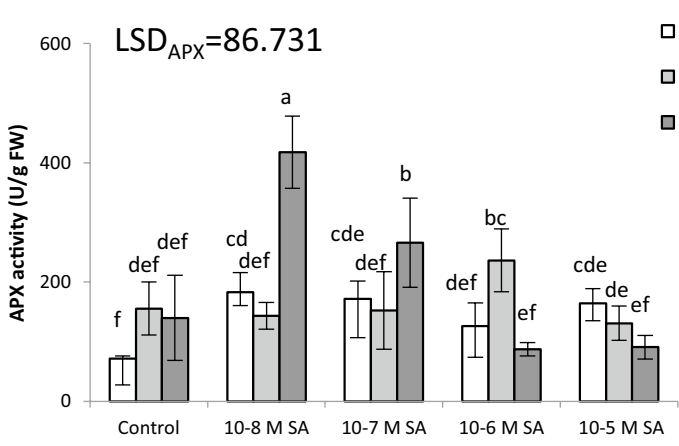

C

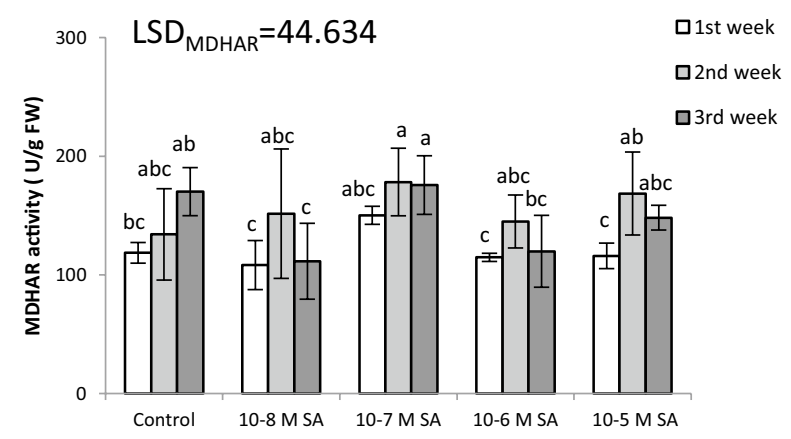

e

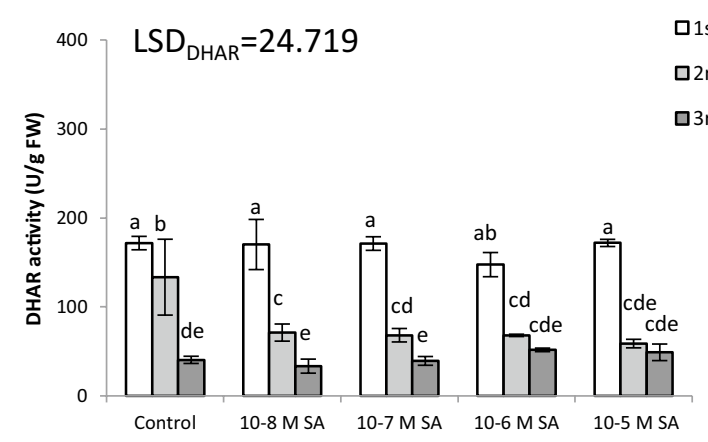

g
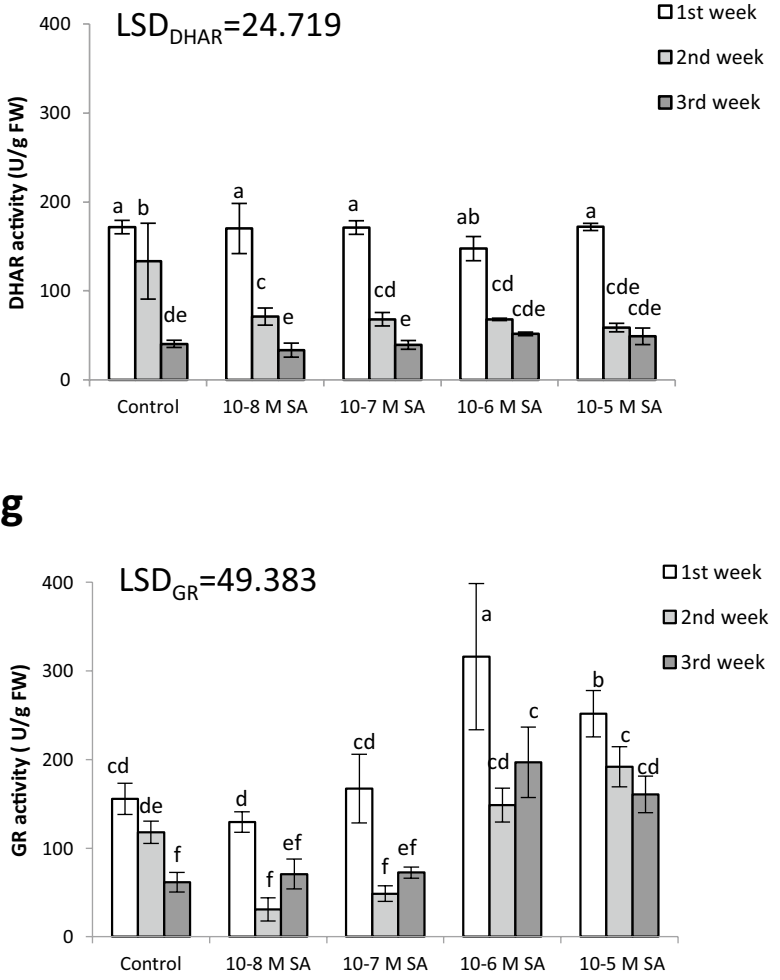

b

\section{Root}
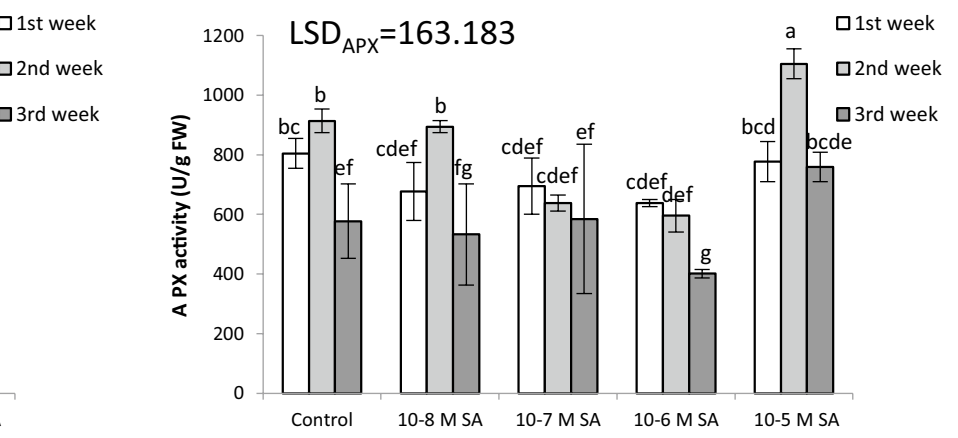

d

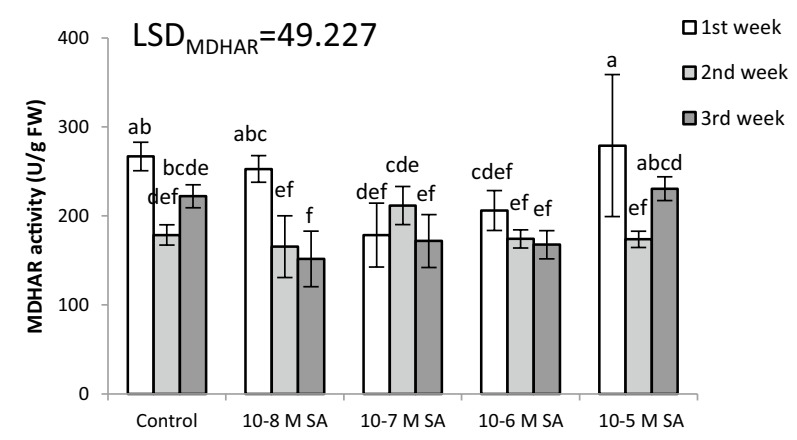

f

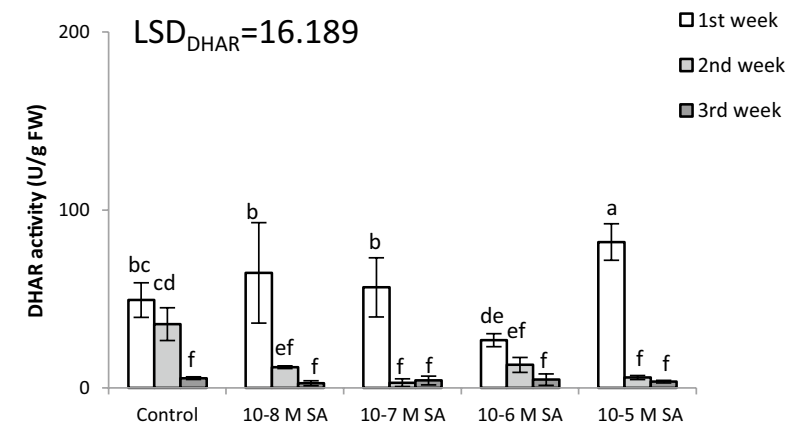

h

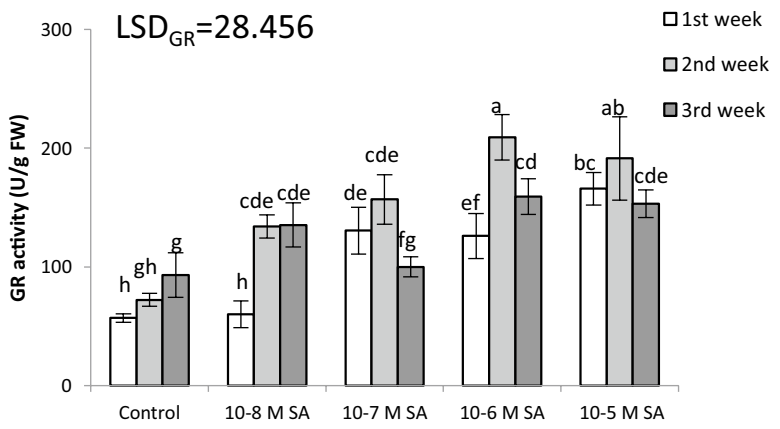


4 Fig. 2 Effects of 3-week-long treatments with $10^{-8}-10^{-5} \mathrm{M}$ SA on the activity of ascorbate peroxidase (APX), monodehydroascorbate reductase (MDHAR), dehydroascorbate reductase (DHAR) and glutathione reductase (GR) in the leaves and roots of 8-week-old Arabidopsis plants. Data are means \pm SD. Columns with different letters are significantly different at $p<0.05$, determined by Duncan's test. Control values before treatments were: a $80.67 \pm 20.8$, b $764.91 \pm 25.1$, c $140.93 \pm 19.5$, d $250.86 \pm 29.5$, e $180.04 \pm 15.1$, f $39.17 \pm 16.5$, g $173.59 \pm 33.4$, h $53.44 \pm 12.6 \mathrm{U} \mathrm{g}^{-1} \mathrm{FW}$, respectively

the highly susceptible redox active Cys residues of proteins, which have much lower pKa values than other protein thiols and usually exist as thiolate anions $\left(-\mathrm{S}^{-}\right)$under physiological pH conditions (D'Autréaux and Toledano 2007; Spadaro et al. 2010; Couturier et al. 2013; Munné-Bosch et al. 2013; Diaz-Vivancos et al. 2015). It has been suggested that enhanced ROS production can temporarily shift the redox potential towards more oxidizing values, which will alter the operational controls of redox-sensitive proteins (Foyer and Noctor 2016). A relatively small global shift in the $E_{G S H}$ is associated with a very large change in gene expression and plant development (Aller et al. 2013; Schnaubelt et al. 2015).

According to our earlier results, supplementation of the hydroponic culture of 5-week-old Arabidopsis thaliana plants with $10^{-6}-10^{-5}$ M SA for 2 weeks resulted in chemical hardening and alleviated the salinity-induced $\mathrm{H}_{2} \mathrm{O}_{2}$ and malondialdehyde accumulation, while the lower $10^{-8}-10^{-7} \mathrm{M}$ SA concentrations insufficiently activated the defence mechanisms, meaning that they did not mitigate the salt stress injury under the subsequently applied $\mathrm{NaCl}$ stress (Horváth et al. 2015). Moreover, in plants treated with $10^{-5}$ and $10^{-6} \mathrm{M} \mathrm{SA}$, the $\mathrm{K}$ content was higher in shoots and roots, while the $\mathrm{Na}$ level was lower than in the $\mathrm{NaCl}$-treated plants without SA pretreatments. In this way, plants should be able to maintain a higher $\mathrm{K} / \mathrm{Na}$ ratio and root growth during salt stress. In contrast, $10^{-7} \mathrm{M} \mathrm{SA}$, when applied as a pretreatment, was unable to hinder $\mathrm{Na}$ accumulation and $\mathrm{K}$ loss during salt stress, resulting in a decreased $\mathrm{K} / \mathrm{Na}$ ratio compared to the salt-treated controls. (The fresh weight, Na content and $\mathrm{Na} / \mathrm{K}$ ratio of plants pretreated with $10^{-8}-10^{-5} \mathrm{M} \mathrm{SA}$, then stressed with $100 \mathrm{mM} \mathrm{NaCl}$ for 1 week, are shown in Tables S1, S2, Supplementary material.) Here, we report that SA treatments enhanced the amount of several non-enzymatic antioxidants, including ASC and glutathione, and increased the activity of enzymes, such as GR (Figs. 1,2). Our results indicate that enhancement of ASC and GSH pools could be the result of the primed state, which can help with the adaptation to different types of stresses (Antoniou et al. 2016). The activation of these antioxidants may contribute to the recovery of the redox potential during a stress event. Pretreatment with SA can help to retain the redox balance, as detected by the $E_{\text {roGFP1 }}^{\prime}$ value, in the salt-stressed plants, even in the $g r l$ mutant plants, which otherwise have a more oxidized redox state (Fig. 3).

The common feature of ASC and glutathione can be summarized as follows: (i) they are abundant and present in plants in millimolar (0.5-10 mM) concentrations; (ii) specific enzymes couple them to the peroxide metabolism; (iii) their oxidized forms are relatively stable; and (iv) recycling by high-capacity enzymes into the reduced forms depends on the key electron carriers, namely, NAD $(\mathrm{P}) \mathrm{H}$ (Noctor and Foyer 1998). It has been suggested that NAD(P)H best serves in the organization and control over energy production pathways, while ASC is the redox molecule that primarily regulates development and glutathione is mainly important for stress defence and signalling (Potters et al. 2010).

By using another redox-sensitive green fluorescent protein construct (GRX1-roGFP2), it has been shown that $E_{\mathrm{GSH}}$ in grl mutants significantly shift towards more oxidizing conditions (Marty et al. 2009). We have found a similar shift in the redox potential of control and salt-stressed $g r l$ plants; however, because of the different properties and sensitivity of the roGFPs, there are some differences between the exact $E$ values of Arabidopsis leaves reported using roGFP2 or roGFP1 (Meyer and Dick 2010). Analysing the redox potential profile of the primary root tip of immersed Arabidopsis seedlings,
Table $1 E_{\text {roGFP1 }}^{\prime}$ during the SA treatment of 5-week old Arabidopsis plants expressing cytosolic roGFP1 in Col-0 or grl mutant background

\begin{tabular}{llll}
\hline & 1 week & 2 weeks & 3 weeks \\
\hline Control & & & \\
roGFP1 & $-294.50 \pm 12.12^{\mathrm{d}}$ & $-283.60 \pm 10.75^{\mathrm{c}}$ & $-270.56 \pm 12.79^{\mathrm{bc}}$ \\
$g r 1 \times$ roGFP1 & $-296.74 \pm 9.70^{\mathrm{d}}$ & $-269.06 \pm 13.68^{\mathrm{bc}}$ & $-261.56 \pm 9.74^{\mathrm{b}}$ \\
$10^{-7}$ M SA & & & \\
roGFP1 & $-294.89 \pm 8.45^{\mathrm{d}}$ & $-275.48 \pm 8.20^{\mathrm{c}}$ & $-263.31 \pm 5.93^{\mathrm{b}}$ \\
$g r 1 \times$ roGFP1 & $-295.24 \pm 7.70^{\mathrm{d}}$ & $-270.26 \pm 9.97^{\mathrm{bc}}$ & $-263.33 \pm 8.09^{\mathrm{b}}$ \\
$10^{-5}$ M SA & & & \\
roGFP1 & $-296.37 \pm 6.03^{\mathrm{d}}$ & $-255.90 \pm 8.20^{\mathrm{ab}}$ & $-269.70 \pm 6.40^{\mathrm{bc}}$ \\
$g r 1 \times$ roGFP1 & $-289.74 \pm 8.39^{\mathrm{d}}$ & $-246.79 \pm 10.67^{\mathrm{a}}$ & $-269.01 \pm 9.45^{\mathrm{b}}$ \\
\hline
\end{tabular}

Data are means \pm SD. Columns with different letters are significantly different at $\mathrm{P}<0.05$, determined by Duncan's test 
a

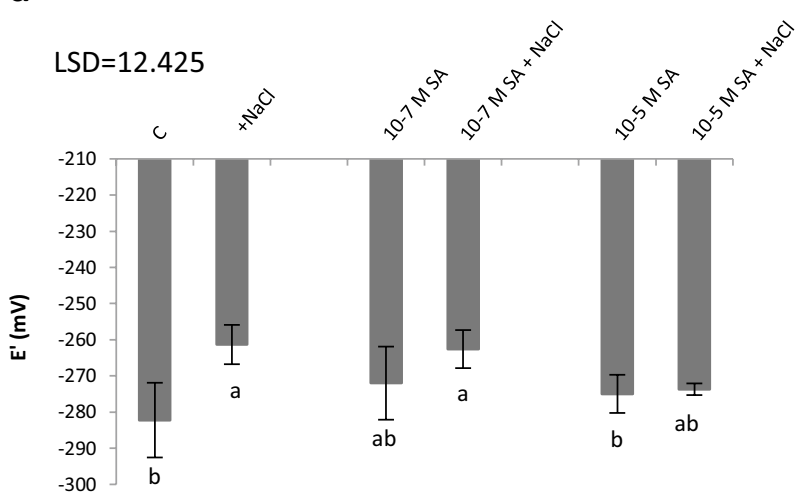

b

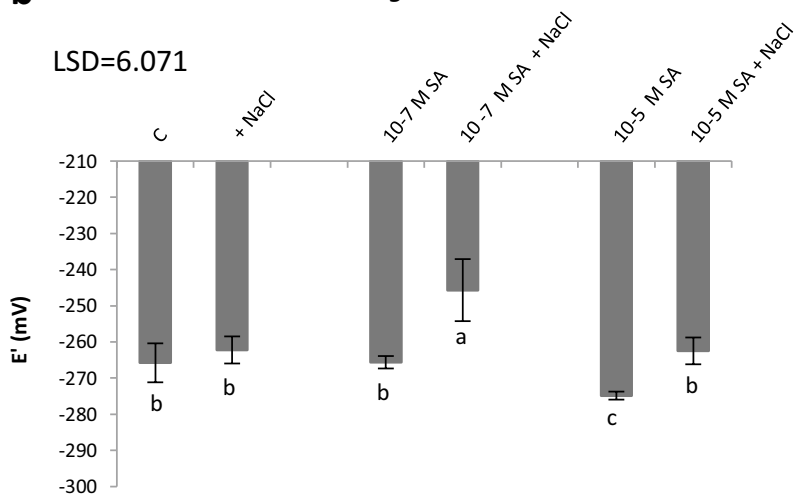

Fig. 3 Redox potential of Arabidopsis Col-0 and grl leaves expressing the c-roGFP1 redox sensor protein after 2-week-long pretreatments with $10^{-7}$ and $10^{-5} \mathrm{M} \mathrm{SA}$, followed by a 1-week-long exposure involving $100 \mathrm{mM} \mathrm{NaCl}$. Data are means \pm SD. Columns with different letters are significantly different at $p<0.05$, determined by Duncan's test

using roGFP1 as the redox sensor, Jiang et al. (2016) reported $E$ values in the range of -270 to $-280 \mathrm{mV}$, which is comparable to our measurement data on hydroponically grown 6- to 8-week-old Arabidopsis plants (Table 1; Fig. 3).

Our results also indicate that, while GR activity increases during SA treatment, the product of GR1 is important, especially in salt stress responses, but it is not a single determinant in the maintenance of redox potential. Marty et al. (2009) suggested that a reduction of GSSG in $g r l$ plants could still be possible on account of the NADPH-dependent thioredoxin (TRX) system, which could work as a backup system for GR1. The significant increase in the glutathione pool, due to salt stress and SA treatments, in our experiments indicated that the biosynthesis of GSH was induced both in the roGFP1-expressing Arabidopsis Col-0 and in the grlxroGFP1 genotypes, but to a higher extent in the latter (Fig. 4). This suggests that GR deficiency can be compensated by the activation of supplemental mechanisms and via an increased GSH pool.
Fig. 4 Changes in reduced and oxidized ascorbate and glutathione (ASC, DHA, GSH and GSSG, respectively) contents and their ratio in the leaves and roots of 8-week-old c-roGFP1-containing Arabidopsis Col-0 and grl leaves after 2-week-long pretreatments with $10^{-7}$ and $10^{-5} \mathrm{M} \mathrm{SA}$, followed by a 1-week-long exposure involving $100 \mathrm{mM} \mathrm{NaCl}$. Data are means \pm SD. Columns with different letters are significantly different at $p<0.05$, determined by Duncan's test

The redox-based reversible post-translational modifications of thiols, e.g., disulphides, $S$-glutathionylation and oxidation of a Cys thiol group into a sulfenic acid (Cys$\mathrm{SOH}$ ), is one of the main signalling functions of ROS, which may act as a regulatory switch in several signal transduction pathways or result in modified biochemical activities (Foyer and Noctor 2005; Ma et al. 2007). A general example of redox-regulated proteins is the NPR1 protein in SA signalling, where the reduced form is active (Mou et al. 2003). On the other hand, the $\gamma$-glutamyl-cysteine synthetase enzyme ( $\gamma$-ECS or GSH1, responsible for the rate-limiting first step in GSH biosynthesis) has proven to be active in its oxidized form (Hicks et al. 2007). This corresponds well with the transient shift towards more positive redox potentials at an SA concentration of $10^{-5} \mathrm{M}$, resulting in the highest GSH contents in pretreated $g r l$ mutants (Table 1). In the case of GR, it has been clearly established that the redox interconversion largely depended on substrate availability. The oxidized form of the enzyme is more stable than the reduced form, ensuring its activity under a more oxidized cellular environment (Rao and Reddy 2008). Similarly, the oxidized form of AtDHAR2 was reported to be more stable than the reduced form, which may ensure the effective activity of the enzymes, even under adverse conditions (Begara-Morales et al. 2015). DHARs reduce dehydroascorbate (DHA) to ASC, while oxidizing GSH into GSSG (Dixon et al. 2002). In this way, DHARs plays an important role in the regulation of the cellular ASC redox status (Chen and Gallie 2004). Waszczak et al. (2014) demonstrated that DHAR activity was maintained in the presence of $1 \mathrm{mM} \mathrm{GSH}$ after adding $1 \mathrm{mM} \mathrm{H}_{2} \mathrm{O}_{2}$; therefore, in this case, the post-translational protein modification protected the protein against oxidative damage. However, we did not measure retained or enhanced DHAR activity in parallel with an increasing GSH pool during SA pretreatment (Fig. 2). In contrast to DHAR, the activity of MDHAR was maintained in all investigated SA concentrations during the 3-week-long treatment. As MDHAR uses NAD $(\mathrm{P}) \mathrm{H}$ as a reductant for the regeneration of ASC (Foyer and Noctor 2011), these results indicate that the NAD(P)H-dependent ASC regeneration by MDHAR became more important during chemical hardening than GSH-dependent DHAR activity. These shifts in enzyme activities involved in ASC regeneration may also contribute to the preservation of the GSH pool. 

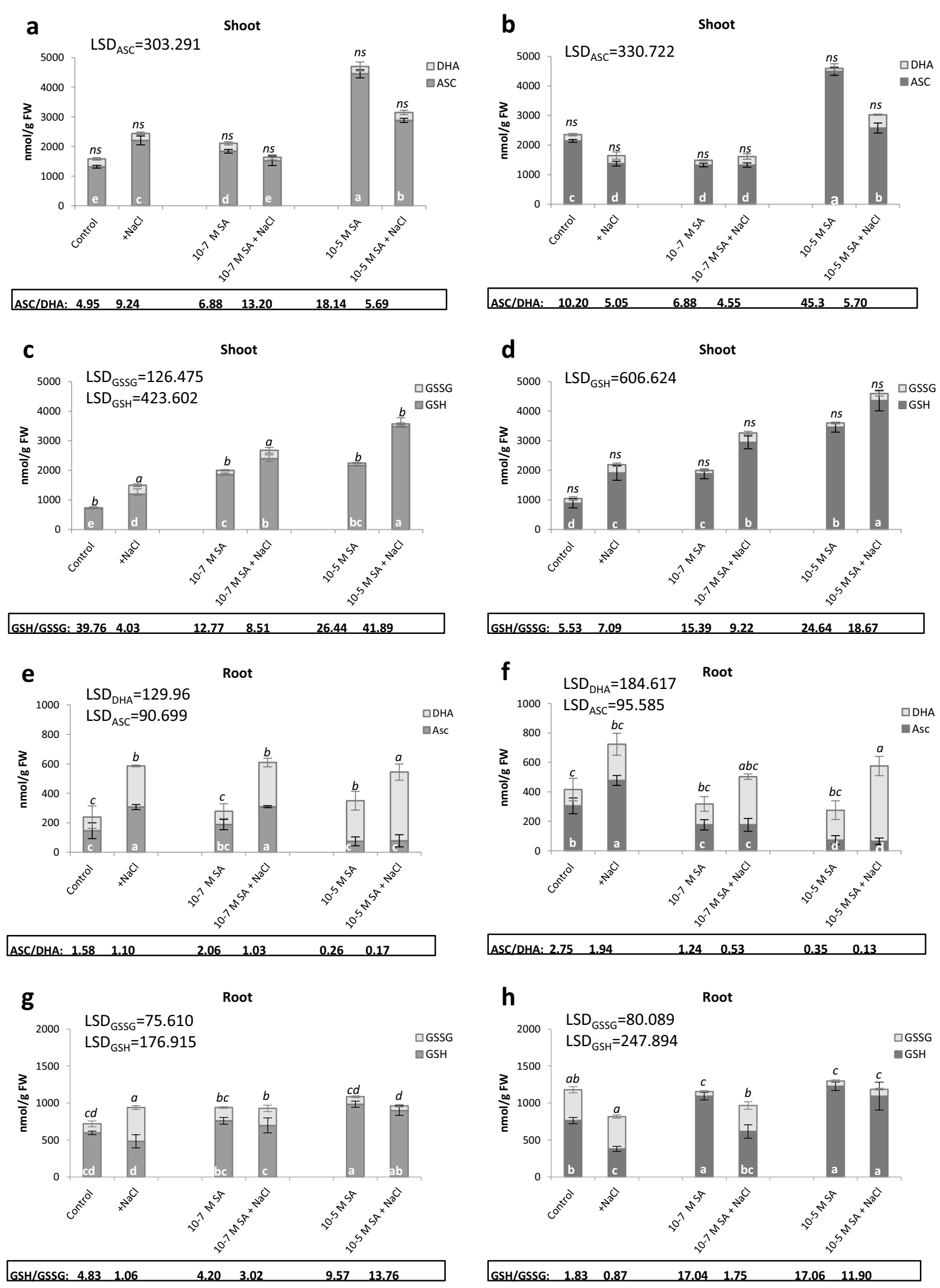
In conclusion, our results indicate that, during chemical hardening with $\mathrm{SA}$, pretreatment in a proper concentration causes a transitional shift in a redox potential towards a more oxidized status in order to realize the primed state. The elevation of ASC, and especially the GSH levels, is prolonged for 2-3 weeks in the case of 5-week-old Arabidopsis plants. The maintained or even increased GSH/ GSSG ratio could facilitate the preservation of the redox potential of plants cells during this period. Although GR activity may have an important role in this process, other mechanisms can substitute the deficiency of the GR1 isoenzyme during chemical hardening, as well as possibly ensuring similar changes in the redox status to support the maintenance of the redox potential, even after applying a subsequent stress treatment. Thus, successful SA-induced priming is associated with the maintenance of redox homeostasis during the exposure of plants to subsequent abiotic stress.

Acknowledgements We would like to thank Dr. M. Schwarzländer for the c-roGFP1-harbouring Arabidopsis seeds. This study was supported by the Hungarian National Research, Development and Innovation Office [Grant Numbers: OTKA K 105956 and NKFI-1 PD 121027] and by the Hungary-Serbia IPA Cross-border Co-operation Programme [HUSRB/1203/221/173]

\section{References}

Aller I, Rouhier N, Meyer AJ (2013) Development of roGFP2-derived redox probes for measurement of the glutathione redox potential in the cytosol of severely glutathione-deficient $\mathrm{rmll}$ seedlings. Front Plant Sci 4:506

Antoniou C, Savvides A, Christou A, Fotopoulos V (2016) Unravelling chemical priming machinery in plants: the role of reactive oxygennitrogen-sulfur species in abiotic stress tolerance enhancement. Curr Opin Plant Biol 33:101-107

Baxter A, Mittler R, Suzuki N (2014) ROS as key players in plant stress signalling. J Exp Bot 65:1229-1240

Beckers GJ, Conrath U (2007) Priming for stress resistance: from the lab to the field. Curr Opin Plant Biol 10:425-431

Begara-Morales JC, Sanchez-Calvo B, Chaki M, Mata-Perez C, Valderrama R, Padilla MN, Lopez-Jaramillo J, Luque F, Corpas FJ, Barroso JB (2015) Differential molecular response of monodehydroascorbate reductase and glutathione reductase by nitration and S-nitrosylation. J Exp Bot 66:5983-5996

Boguszewska D, Zagdańska B (2012) ROS as signaling molecules and enzymes of plant response to unfavorable environmental conditions. In: Lushchak V (ed) Oxidative stress-molecular mechanisms and biological effects, InTech, Rijeka, pp 341-362, http:// www.intechopen.com, ISBN: 978-953-51-0554-1

Chen Z, Gallie DR (2004) The ascorbic acid redox state controls guard cell signaling and stomatal movement. Plant Cell 16:1143-1162

Couturier J, Chibani K, Jacquot JP, Rouhier N (2013) Cysteine-based redox regulation and signaling in plants. Front Plant Sci 4:105

Csiszár J, Horváth E, Váry Z, Gallé Á, Bela K, Brunner Sz, Tari I (2014) Glutathione transferase supergene family in tomato: salt stress-regulated expression of representative genes from distinct
GST classes in plants primed with salicylic acid. Plant Physiol Biochem 78:15-26

D'Autréaux B, Toledano MB (2007) ROS as signalling molecules: mechanisms that generate specificity in ROS homeostasis. Nat Rev Mol Cell Biol 8:813-824

Dat J, Vandenabeele S, Vranova E, Van Montagu M, Inze D, Van Breusegem F (2000) Dual action of the active oxygen species during plant stress responses. Cell Mol Life Sci 57:779-795

Delorme-Hinoux V, Bangash SAK, Meyer AJ, Reichheld JP (2016) Nuclear thiol redox systems in plants. Plant Sci 243:84-95

Diaz-Vivancos P, de Simone A, Kiddle G, Foyer CH (2015) Glutathione-linking cell proliferation to oxidative stress. Free Radic Biol Med 89:1154-1164

Ding SH, Lu QT, Zhang Y, Yang ZP, Wen XG, Zhang LX, Lu CM (2009) Enhanced sensitivity to oxidative stress in transgenic tobacco plants with decreased glutathione reductase activity leads to a decrease in ascorbate pool and ascorbate redox state. Plant Mol Biol 69:577-592

Dixon DP, Davis BG, Edwards R (2002) Functional divergence in the glutathione transferase superfamily in plants-identification of two classes with putative functions in redox homeostasis in Arabidopsis thaliana. J Biol Chem 277:30859-30869

Foyer CH, Noctor G (2005) Redox homeostasis and antioxidant signaling: a metabolic interface between stress perception and physiological responses. Plant Cell 17:1866-1875

Foyer CH, Noctor G (2011) Ascorbate and glutathione: the heart of the redox hub. Plant Physiol 155:2-18

Foyer CH, Noctor G (2016) Stress-triggered redox signalling: what's in pROSpect? Plant Cell Environ 39:951-964

Gémes K, Poór P, Horváth E, Kolbert Zs, Szopkó D, Szepesi Á, Tari I (2011) Cross-talk between salicylic acid and NaCl-generated reactive oxygen species and nitric oxide in tomato during acclimation to high salinity. Physiol Plant 142:179-192

Gill SS, Anjum NA, Hasanuzzaman M, Gill R, Trivedi DK, Ahmad I, Pereira E, Tuteja N (2013) Glutathione and glutathione reductase: a boon in disguise for plant abiotic stress defense operations. Plant Physiol Biochem 70:204-212

Han Y, Chaouch S, Mhamdi A, Queval G, Zechmann B, Noctor GD (2013) Functional analysis of Arabidopsis mutants points to novel roles for glutathione in coupling $\mathrm{H}_{2} \mathrm{O}_{2}$ to activation of salicylic acid accumulation and signaling. Antioxid Redox Signal 18:2106-2121

Hanson GT, Aggeler R, Oglesbee D, Cannon M, Capaldi RA, Tsien RY, Remington SJ (2004) Investigating mitochondrial redox potential with redox-sensitive green fluorescent protein indicators. J Biol Chem 279:13044-13053

Hayat Q, Hayat S, Irfan M, Ahmad A (2010) Effect of exogenous salicylic acid under changing environment: a review. Environ Exp Bot 68:14-25

Hicks LM, Cahoon RE, Bonner ER, Rivard RS, Sheffield J, Jez JM (2007) Thiol-based regulation of redox-active glutamate-cysteine ligase from Arabidopsis thaliana. Plant Cell 19:2653-2661

Horváth E, Szalai G, Janda T (2007) Induction of abiotic stress tolerance by salicylic acid signaling. J Plant Growth Regul 26(3):290-300

Horváth E, Brunner Sz, Bela K, Papdi Cs, Szabados L, Tari I, Csiszár J (2015) Exogenous salicylic acid-triggered changes in the glutathione transferases and peroxidases are key factors in the successful salt stress acclimation of Arabidopsis thaliana. Funct Plant Biol 42:1129-1140

Hossain MA, Nakano Y, Asada K (1984) Monodehydroascorbate reductase in spinach chloroplasts and its participation in regeneration of ascorbate for scavenging hydrogen peroxide. Plant Cell Physiol 25:385-395 
Janda T, Szalai G, Tari I, Páldi E (1999) Hydroponic treatment with salicylic acid decreases the effects of chilling injury in maize (Zea mays L.) plants. Planta 208:175-180

Jiang K, Schwarzer C, Lally E, Zhang S, Ruzin S, Machen T, Remington SJ, Feldman L (2006) Expression and characterization of a redox-sensing green fluorescent protein (reduction-oxidation-sensitive green fluorescent protein) in Arabidopsis. Plant Physiol 141:397-403

Jiang K, Moe-Lange J, Hennet L, Feldman LJ (2016) Salt stress affects the redox status of Arabidopsis root meristems. Front Plant Sci 7:81

Jimenez A, Hernandez JA, del Rio LA, Sevilla F (1997) Evidence for the presence of the ascorbate-glutathione cycle in mitochondria and peroxisomes of pea leaves. Plant Physiol 114:275-284

Ma LH, Takanishi CL, Wood MJ (2007) Molecular mechanism of oxidative stress perception by the Orp1 protein. J Biol Chem 282:31429-31436

Marty L, Siala W, Schwarzländer M, Fricker MD, Wirtz M, Sweetlove LJ, Meyer Y, Meyer AJ, Reichheld JP, Hell R (2009) The NADPH-dependent thioredoxin system constitutes a functional backup for cytosolic glutathione reductase in Arabidopsis. Proc Natl Acad Sci USA 106:9109-9114

Meyer AJ, Dick TP (2010) Fluorescent protein-based redox probes. Antioxid Redox Signal 13:621-650

Meyer AJ, Brach T, Marty L, Kreye S, Rouhier N, Jacquot JP, Hell R (2007) Redox-sensitive GFP in Arabidopsis thaliana is a quantitative biosensor for the redox potential of the cellular glutathione redox buffer. Plant J 52:973-986

Mhamdi A, Hager J, Chaouch S, Queval G, Han Y, Taconnat L, Saindrenan P, Gouia H, Issakidis-Bourguet E, Renou JP, Noctor G (2010) Arabidopsis GLUTATHIONE REDUCTASE1 plays a crucial role in leaf responses to intracellular hydrogen peroxide and in ensuring appropriate gene expression through both salicylic acid and jasmonic acid signaling pathways. Plant Physiol 153:1144-1160

Mou Z, Fan W, Dong X (2003) Inducers of plant systemic acquired resistance regulate NPR1 function through redox changes. Cell 113:935-944

Munné-Bosch S, Queval G, Foyer CH (2013) The impact of global change factors on redox signaling underpinning stress tolerance. Plant Physiol 161:5-19

Nakano Y, Asada K (1987) Purification of ascorbate peroxidase in spinach chloroplasts: its inactivation in ascorbate-depleted medium and reactivation by monodehydroascorbate radical. Plant Cell Physiol 28:131-140

Noctor G (2006) Metabolic signalling in defence and stress: the ecentral roles pof soluble redox couples. Plant Cell Environ 29:409-425

Noctor G, Foyer CH (1998) Ascorbate and glutathione: keeping active oxygen under control. Annu Rev Plant Physiol Plant Mol Biol 49:249-279

Noctor G, Queval G, Mhamdi A, Chaouch S, Foyer CH (2011) Glutathione. Arabidopsis Book, 9:1-32

Noctor G, Mhamdi A, Chaouch S, Han Y, Neukermans J, MarquezGarcia B, Queval G, Foyer CH (2012) Glutathione in plants: an integrated overview. Plant Cell Environ 35:454-484

Popova LP, Maslenkova LT, Yordanova RY, Ivanova AP, Krantev AP, Szalai G, Janda T (2009) Exogenous treatment with salicylic acid attenuates cadmium toxicity in pea seedlings. Plant Physiol Biochem 47:224-231

Potters G, Horemans N, Jansen MAK (2010) The cellular redox state in plant stress biology - A charging concept. Plant Physiol Bioch 48(5):292-300. https://doi.org/10.1016/j.plaphy.2009.12.007
Rao AC, Reddy AR (2008) Glutathione reductase: a putative redox regulatory system in plant cells. In: Khan NA, Singh S, Umar S (eds) Sulfur assimilation and abiotic stress in plants. Springer, Heidelberg, pp 111-147

Rosenwasser S, Rot I, Meyer AJ, Feldman L, Jiang K, Friedman H (2010) A fluorometer-based method for monitoring oxidation of redox-sensitive GFP (roGFP) during development and extended dark stress. Physiol Plant 138:493-502

Savvides A, Ali S, Tester M, Fotopoulos V (2016) Chemical priming of plants against multiple abiotic stresses: mission possible? Trends Plant Sci 21:329-340

Schnaubelt D, Queval G, Dong Y, Diaz-Vivancos P, Makgopa ME, Howell G, De Simone A, Bai J, Hannah MA, Foyer CH (2015) Low glutathione regulates gene expression and the redox potentials of the nucleus and cytosol in Arabidopsis thaliana. Plant Cell Environ 38:266-279

Schwarzländer M, Fricker MD, Müller C, Marty L, Brach T, Novak J, Sweetlove LJ, Hell R, Meyer AJ (2008) Confocal imaging of glutathione redox potential in living plant cells. J Microsc 231:299-316

Shalata A, Neumann PM (2001) Exogenous ascorbic acid (vita$\min \mathrm{C}$ ) increases resistance to salt stress and increases resistance to salt stress and reduces lipid peroxidation. J Exp Bot 52:2207-2211

Shirasu K, Nakajima H, Rajashekar K, Dixon RA, Lamb C (1997) Salicylic acid potentiates an agonist-dependent gain control that amplifies pathogen signal in the activation of defense mechanisms. Plant Cell 9:261-270

Shu DF, Wang LY, Duan M, Deng YS, Meng QW (2011) Antisensemediated depletion of tomato chloroplast glutathione reductase enhances susceptibility to chilling stress. Plant Physiol Biochem 49:1228-1237

Spadaro D, Yun BW, Spoel SH, Chu C, Wang YQ, Loake GJ (2010) The redox switch: dynamic regulation of protein function by cysteine modifications. Physiol Plant 138:360-371

Szepesi Á, Csiszár J, Gallé Á, Gémes K, Poór P, Tari I (2008) Effects of long-term salicylic acid pre-treatment on tomato (Lycopersicon esculentum Mill. L.) salt stress tolerance: changes in glutathione S-transferase activities and anthocyanin contents. Acta Agron Hung 56:129-138

Szepesi Á, Csiszár J, Gémes K, Horváth E, Horváth F, Simon ML, Tari I (2009) Salicylic acid improves acclimation to salt stress by stimulating abscisic aldehyde oxidase activity and abscisic acid accumulation, and increases $\mathrm{Na}^{+}$content in leaves without toxicity symptoms in Solanum lycopersicum L. J Plant Physiol 166:914-925

Tada Y, Spoel SH, Pajerowska-Mukhtar K, Mou ZL, Song JQ, Wang C, Zuo JR, Dong XN (2008) Plant immunity requires conformational charges of NPR1 via S-nitrosylation and thioredoxins. Science 321:952-956

Tanou G, Filippou P, Belghazi M, Job D, Diamantidis G, Fotopoulos $\mathrm{V}$, Molassiotis A (2012) Oxidative and nitrosative-based signaling and associatedpost-translational modifications orchestrate the acclimation of citrus plants to salinity stress. Plant $\mathrm{J}$ 72:585-599

Tari I, Csiszár J, Szalai G, Horváth F, Pécsváradi A, Kiss G, Szepesi Á, Szabó M, Erdei L (2002) Acclimation of tomato plants to salinity stress after a salicylic acid pre-treatment. Acta Biol Szeged 46:55-56

Tari I, Csiszár J, Horváth E, Poór P, Takács Z, Szepesi Á (2015) Alleviation of the adverse effect of salt stress in tomato by salicylic acid shows time- and organ-specific antioxidant response. Acta Biol Crac Bot 57:1-10 
Tsai YC, Hong CY, Liu LF, Kao CH (2005) Expression of ascorbate peroxidase and glutathione reductase in roots of rice seedlings in response to $\mathrm{NaCl}$ and $\mathrm{H}_{2} \mathrm{O}_{2}$. J Plant Physiol 162:291-299

Tzafrir I, Pena-Muralla R, Dickerman A, Berg M, Rogers R, Hutchens S, Sweeney TC, McElver J, Aux G, Patton D, Meinke D (2004) Identification of genes required for embryo development in Arabidopsis. Plant Physiol 135:1206-1220
Waszczak C, Akter S, Eeckhout D, Persiau G, Wahni K, Bodra N, Van Molle I, De Smet B, Vertommen D, Gevaert K, De Jaeger G, Van Montagu M, Messens J, Van Breusegem F (2014) Sulfenome mining in Arabidopsis thaliana. Proc Natl Acad Sci USA 111:11545-11550 